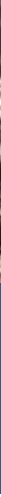

CIFOR infobrief provides concise, accurate, peer-reviewed information on current topics in forest research

\title{
Forests and Human Health
}

Up to 350 million people live in or near forests, and illness is a daily reality for many. Malaria, Ebola, river blindness, query fever, elephantiasis and a host of other diseases are associated with communities who live in forest areas. Frequently, these diseases become more prevalent when the forests are degraded or cleared.

The relationship between human health and tropical forests is highly complex, and influenced by a whole range of factors, including diet, poverty, climate change and land-use practices. A recent CIFOR report has shed new light on the ways in which tropical forests affect health, both within and beyond forests. This infobrief provides a short summary.

\section{Key points}

- Tropical forests provide food, medicine and fuelwood for many millions of people. But there is a downside to forest life: many suffer from debilitating and often fatal illnesses. Forest clearance sometimes makes life better, for example by transforming forests into productive farmland; but deforestation, besides causing environmental problems, can also lead to the loss of wild foods and encourage the spread of diseases.

- Diseases which originate in forests - an obvious example is HIV/AIDS - can spread to surrounding areas. Likewise, diseases from outside forests can have a serious impact on forest-dwelling communities.

- Climate change could dramatically affect the availability of forests foods and medicinal plants in future. It could also lead to an increase in some diseases in forest areas.

- Forest communities are often poorly served by health services. It is impossible to supply trained personnel to every village, and the solution lies in promoting interdisciplinary efforts that combine traditional healing with modern health care.

\section{Forests and food}

Although forests are often totally unsuited to conventional agriculture, they can be a rich source of food for local communities, providing nuts, berries, roots, mushrooms and animals ranging in size from palm weevils to elephants. Many forest species contain nutrients such as vitamins A and C, niacin and iron, all of which are important for good health. Forests also provide local communities with livestock fodder, and in many countries they provide cooking fuel for most of the population. Forests have the potential to provide more food than they do at present through selective crop breeding and, more controversially, genetic manipulation.

By providing food in times of war and scarcity, forests can act as a safety net. But they can also act as a poverty trap, as forest communities are often excluded from development processes and find it hard to earn a living. This means they are particularly dependent on forest foods. This, in turn, can lead to the over-exploitation of edible species, with serious consequences for both wildlife and humans. Commercial hunting to supply urban markets and logging camps is also threatening wildlife populations in many tropical countries. For example, the bushmeat trade in Cameroon and Ghana has led to a decline of primates and large ungulates in many areas.

Some forest foods may pose a threat to human health. Tropical roots such as cassava, which contains small amounts of cyanide, are poisonous unless properly cooked, and carcinogenic aflatoxins are associated with corn and other foods contaminated by fungal growth. The handling of bush meat can lead to the spread of viral diseases.

Food security-having enough to eat - is a serious problem in forest areas, and seasonal fluctuations in the availability of wild foods can lead to a cycle of plenty and want. The unequal

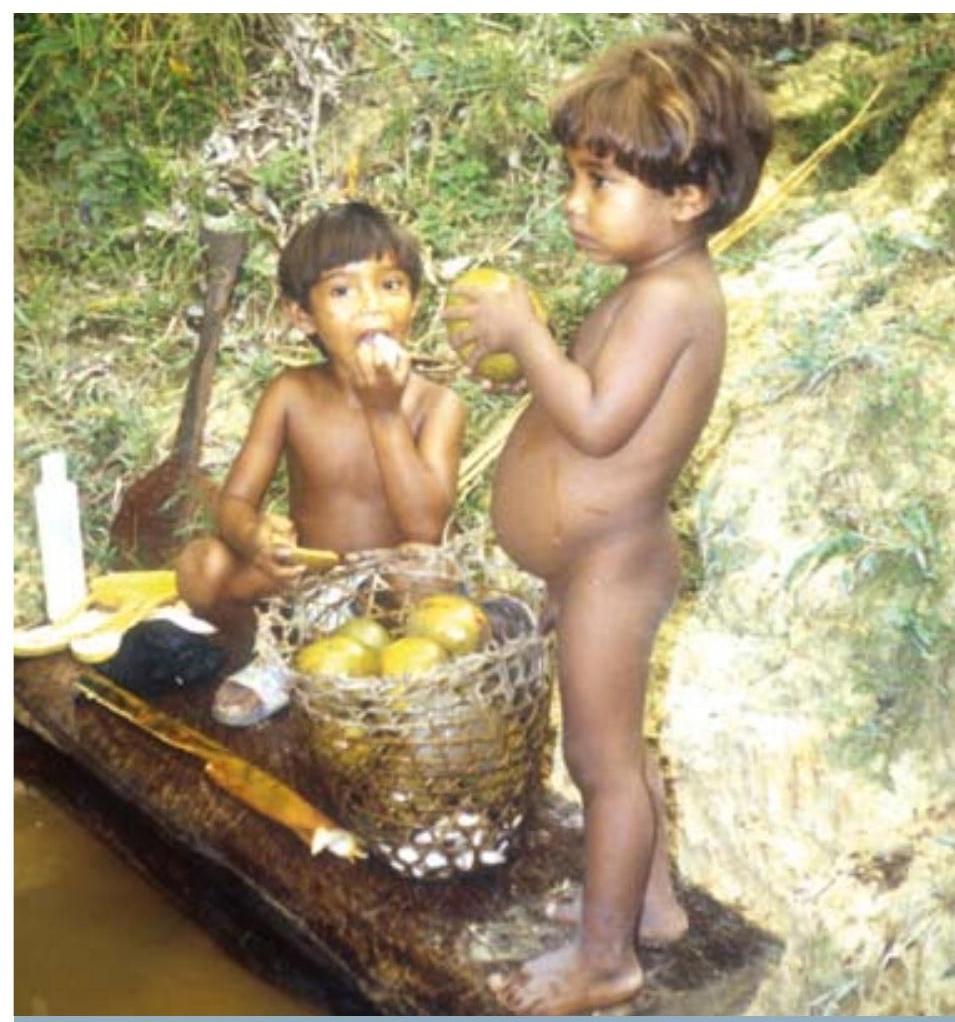

Despite the seasonal availability of wild fruits such as bacuri (Platonia insignis) a child from Quiandeua, Pará, Brazil demonstrates the potbelly characteristic of malnutrition (Photo by Patricia Shanley) 
distribution of food within households often means women and girls are particularly at risk of malnutrition, and therefore more susceptible to disease. Women and children are also much more likely to suffer from serious respiratory problems which result from cooking on wood fires.

\section{Forests and disease}

Tropical diseases affect half a billion people each year, killing around 20 million. Many of these diseases affect forest communities and their prevalence is frequently influenced by deforestation, mining, dam building and other activities.

Malaria, which is spread by mosquitoes, is a major killer in tropical countries. At any one time some 500 million people suffer from malaria, with 70 per cent of cases occurring in Africa. The relationship between the disease and forests is complex. In Nepal and Panama, forest clearance has enabled human populations to occupy areas previously made uninhabitable by malaria. However, the exploitation of forests can also lead to an increase in malaria when logging activities create standing water where mosquitoes can breed.

HIV/AIDS is a forest disease in the sense that the virus jumped from chimpanzees to humans in central Africa. As it is primarily transmitted through sexual contact, it recognises no geographical boundaries. It has claimed over 25 million lives, most in Africa, and devastated the economies of many sub-Saharan countries. Poverty, immigration, prostitution, the use of rape as a weapon of war and many other factors have led to the spread of HIV/AIDS. In forest areas, logging and mining roads have brought the disease to remote villages.

Certain diseases have been closely linked to ecological degradation and forest loss (See Table 1). In Africa, these include Ebola, yellow fever and river blindness. In South America, the clearance of forests to make way for cattle ranching has led to dramatic increases in the populations of vampire bats, a natural host for rabies, and Chagas disease has been linked to immigration and forest clearance. Dam building and irrigation schemes in forest areas have led to increases in malaria, guinea worm, dengue fever and plague.

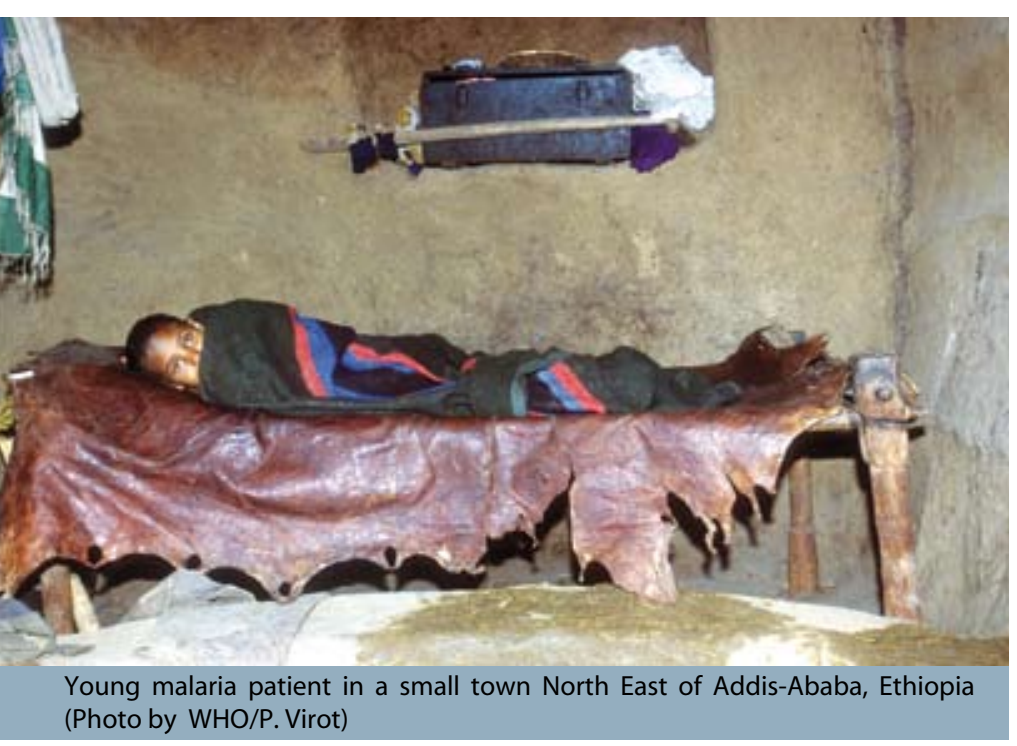

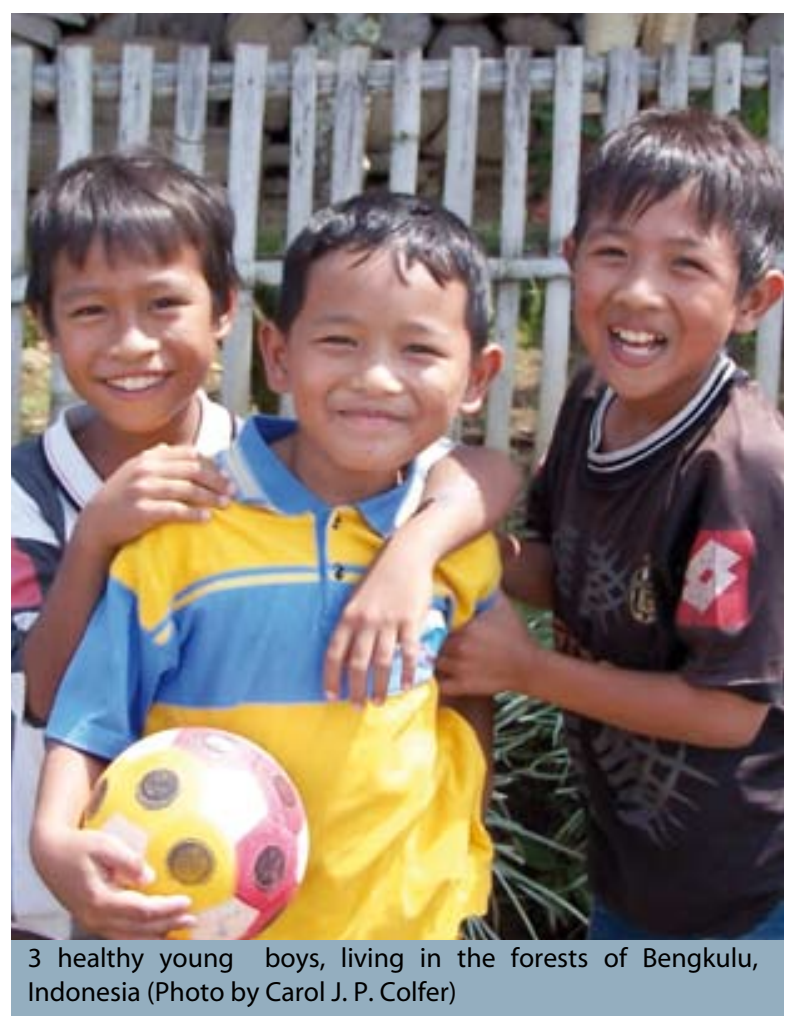

Many forested regions are rich in minerals, and mining activities have affected the health of local communities in various ways. Gold mining, for example, is frequently associated with mercury poisoning, which lowers resistance to disease and can cause insanity. Mercury is used in the processing of gold, and is found in dangerously high levels in water courses and fish in Amazonia, the Philippines and elsewhere.

The exploitation of minerals, timber and other natural resources is invariably associated with significant movements of people in and out of forest areas. Settlers from outside can introduce forest dwellers to diseases to which they have little or no immunity. At the same time, the settlers may be exposed to forest diseases for the first time. This can increase the health risks for both populations. Evidence suggests that when forests are cleared for farming and ranching, the health of forest people generally suffers, in the short term at least.

\section{Forests and medicine}

A survey of the 150 most commonly prescribed drugs in the United States found that 57 per cent contained at least one active compound derived from nature. Many of these will have come from tropical forests, which have yielded contraceptives, muscle relaxants, anti-bacterial compounds, aphrodisiacs and drugs used to treat heart failure, malaria, cancer and other diseases.

Local people in tropical forests have considerable knowledge of medicinal plants, and in many areas traditional practitioners are the main providers of health care. Evidence of the efficacy of some traditional remedies is growing, and medicinal plants from tropical regions are now being used around the world. 
As a result of the growing demand for medicinal plants, it is thought that around half of the 20,000 species involved are threatened by extinction. For example, populations of Prunus africana, whose bark is used in the treatment of prostate trouble, have declined dramatically in Cameroon. A similar story can be told for many other species.

Considerable controversy surrounds the harvesting of medicinal plants to supply the pharmaceutical industry. Forest communities, it is said, are inadequately compensated both for their knowledge and for the use of plants harvested within their territory. Drug companies are generally reluctant to share information about their activities, and attempts to work with forest communities when prospecting for new medicines have yielded mixed results.

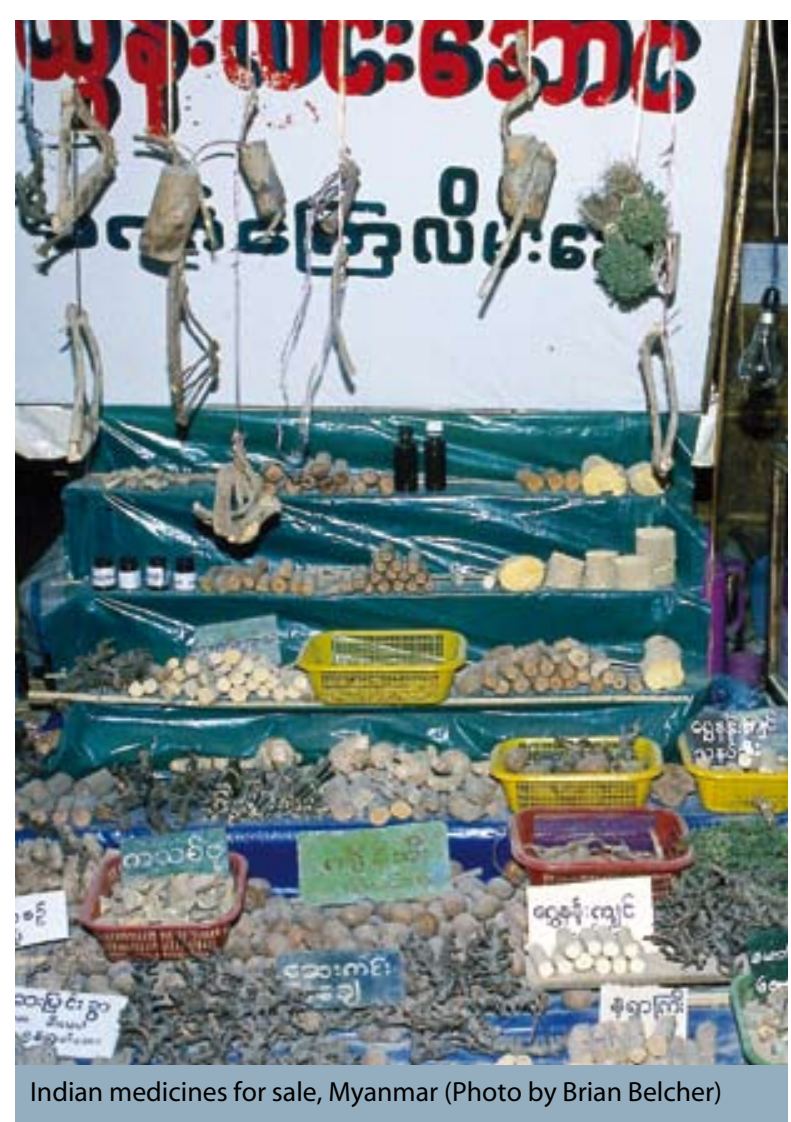

\section{Forests and culture}

Cultures vary enormously from place to place; yet they are mutable, and people change. However, all human beings - regardless of whether they live in remote forest areas or busy metropolises - are enmeshed in, and dependent on, their own cultures for their mental and social well-being. As a general rule, rapid and uncontrolled cultural change tends to harm people's health, and may harm the environment.

This is precisely what is happening to many forest communities. Numerous studies have shown that rapid development - caused, for example, by the opening up of forests for mining, timber extraction and agricultural settlement - can lead to an increase in feelings of depression and hopelessness, as well as the loss of important local knowledge and resources.
Effective communication with forest peoples requires an understanding of, and respect for, their world views. Native knowledge about foods and medicines could undoubtedly benefit Western health professionals. Just as significantly, a wider recognition of the value of native knowledge could contribute to the self-confidence of forest peoples, with positive implications for their mental health.

\section{How can the health of forest people be improved?}

Health professionals could learn more about the health needs of forest dwellers and expand health care delivery in forest areas. They could advise on hygiene and diet, and encourage people to reduce their consumption of fish from rivers contaminated with mercury and other pollutants. They could also provide information about how to avoid HIV/AIDS and about the potential dangers of wildlife-human contact.

Native health systems based on the practices of traditional healers could be used to improve community health if they and health professionals combined traditional and modern health care systems.

In some forest cultures, females experience many disadvantages. Health professions need to explain the links between the status of women and the health of families, and take particular care of women during vulnerable periods like pregnancy and nursing. Family planning programmes could improve family health and reduce pressure on food resources.

Forest and natural resource managers need to ensure that forest products which contribute to human health and welfare are wisely used. Among other things, they should draw up management plans to conserve medicinal plants. Resource managers could also benefit from studying the ways in which native peoples have sustainably managed their forests.

Resource managers should work with health professionals and local people to ensure that families who depend on forest products, including the very poor and

Table 1. Major diseases and their links to forests

\begin{tabular}{l|l}
\hline $\begin{array}{l}\text { Diseases associated with } \\
\text { deforestation or ecological } \\
\text { degradation }\end{array}$ & $\begin{array}{l}\text { Diseases associated with } \\
\text { dams, irrigation or agricultural } \\
\text { development }\end{array}$ \\
\hline Chagas disease & Dengue fever \\
\hline Dengue fever & Dracunculiasis (Guinea worm) \\
\hline Ebola virus & Leishmaniasis \\
\hline Kyasanur forest disease & Lymphatic filariasis (elephantiasis) \\
\hline Lassa virus & Malaria \\
\hline Leishmaniasis & Plague \\
\hline Loa loa & Schistosomiasis \\
\hline Malaria & \\
\hline Marburg virus & \\
\hline Onchocerciasis (river blindness) & \\
\hline Oropouche fever & \\
\hline Plague & \\
\hline Rabies & \\
\hline Schistosomiasis & \\
\hline Yellow fever & \\
\hline
\end{tabular}

Source: See Colfer et al. 2006. Forests and Human Health: Assessing the Evidence, Table 4. CIFOR, Bogor, Indonesia. 
those suffering from HIV/AIDS, have access to forest foods and medicines. Changes in logging practice could help to slow the spread of HIV/AIDS by structuring logging activities so that loggers can bring their families with them, and reduce malaria by preventing mosquitoes from breeding in pools. Resource managers should also consider analysing soils to detect mercury pollution and deficiencies in iodine, calcium, iron and vitamin B12. Where appropriate, they should monitor wildlife that transmits diseases.

Development planners need to ensure that local people's subsistence needs are met when forests are subject to land-use change.They should also consider the livelihoods of forest dwellers before forests are cleared to make way for other uses. To reduce the adverse health impact of major land-use changes, they should consider establishing incomegenerating projects and providing extension services and appropriate training programmes.

When developers and pharmaceutical companies use the knowledge of local people, and exploit their forests, they should share the profits. At a more prosaic level, helping households to switch from burning wood to using more efficient, less polluting fuels would improve the health of both people and forests.

Government agencies should monitor disease outbreaks and send trained teams into forest areas when needed. Companies who exploit forest resources, such as those involved in logging and mining, should be encouraged or required to use environmentally sound practices. Mining companies should be encouraged to limit the use of mercury in gold processing.

Conserving forest ecosystems would help to preserve medicinal plants and animals, ensuring their use for future generations. Government agencies should also be encouraged to protect forest cultures as part of a global effort to maintain cultural diversity. However, a one-sizefits-all approach will not be effective. Governments need to tailor their policies and services to suit different cultures. Concerted effort should be made to improve the status of marginalised groups, including women and girls.

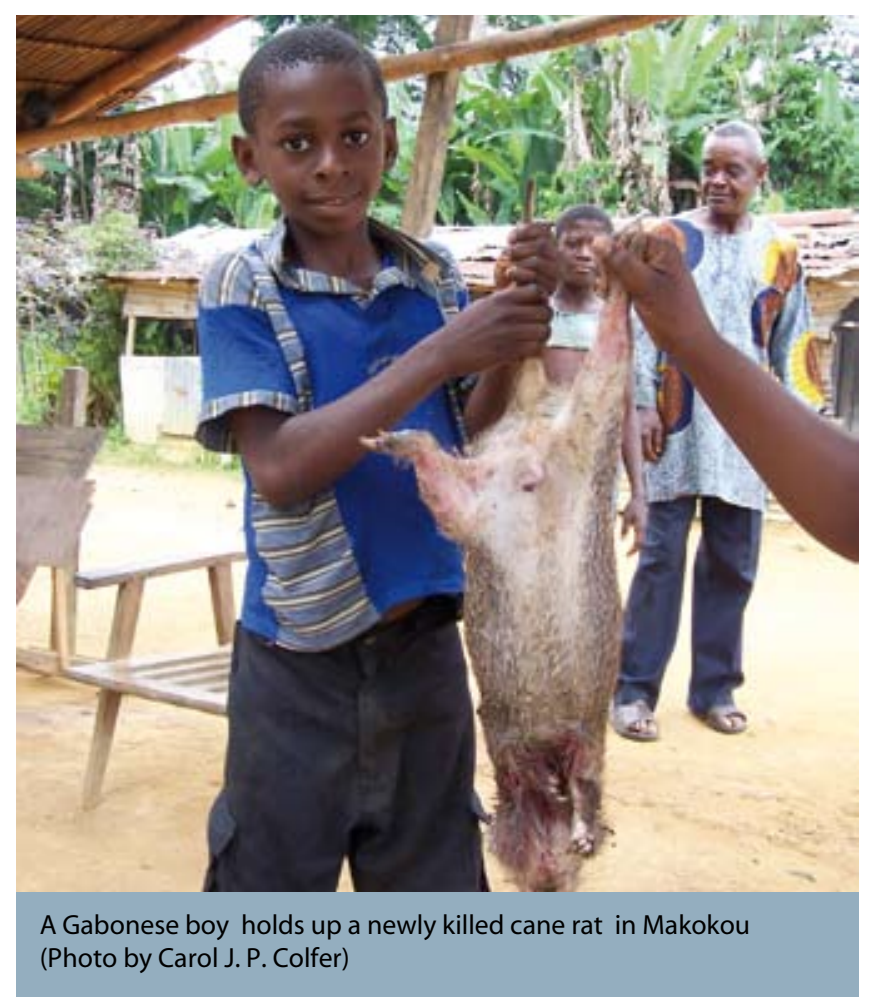

\section{For more information}

This infobrief is based on CIFOR Occasional Paper No.45, Forests and Human Health: Assessing the Evidence (2006), by Carol J. Pierce Colfer, Douglas Sheil and Misa Kishi. The extensive report examines the state of human health in forests and the causal links between forests and human health, with a focus on four topics.

- Forest foods: human dependence on forest foods, their nutritional contributions and nutrition-related problems that affect forest peoples.

- Disease and other health problems: HIV/AIDS, malaria, Ebola, mercury poisoning and some 20 other tropical diseases and health problems related to forests.

- Medicinal products: the biophysical properties of medicinal species, human uses of medicinal forest products, and the roles of traditional healers, with a discussion of the conflicts over the distribution of profits from forest medicines.

- Cultural interpretations of human health among forest peoples: holistic world views that impinge on health and indigenous knowledge.

The report concludes with observations about the current state of our knowledge, policy recommendations and suggestions for future research. For a copy of Forests and Human Health, contact Nia Sabarniati at n.sabarniati@cgiar.org

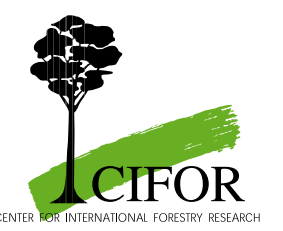

office: Jalan CIFOR, Situ Gede, Sindang Barang, Bogor Barat 16680 , Indonesia mailing: P. O. Box. 6596 JKPWB, Jakarta 10065 , Indonesia
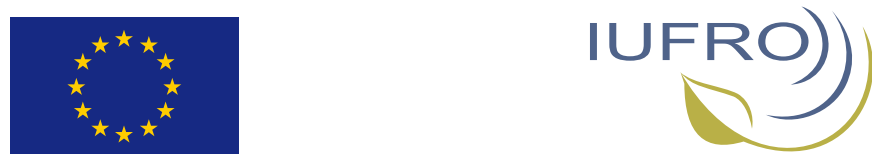

Tel: +62(251) 622622 Fax: +62(251) 622100 E-mail: cifor@cgiar.org Website: www.cifor.cgiar.org
Cover photos by Miriam van Heist, Carol J.P. Colfer,

Koen Kusters, Daniel Tiveau and Edmond Dounias

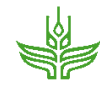

CGIAR 